\title{
COMMUNICATION FAILURES IN NETFLIX DRAMA SERIES "13 REASONS WHY": A PRAGMATIC ANALYSIS
}

\author{
Astri Wulandari, Brigitta Shinta Hapsari and Barli Bram \\ Sanata Dharma University, Indonesia \\ astriwulandari1994@gmail.com, bshintahapsari@gmail.com and barli@usd.ac.id \\ DOI: https://doi.org/10.24071/ijhs.2018.010212
}

received 26 December 2017; revised 14 January 2017; accepted 26 February 2018

\begin{abstract}
Language and linguistics are vital in people's daily conversation. However, because of some causes, there are some misunderstandings or pragmatic failures which may appear in communication among people. Many studies have looked into the pragmatic failures between native speakers and non-native speakers but this study investigates pragmatic failures in Netflix TV drama series " 13 Reasons Why". It aims to discover pragmatic failures that happened in the drama and their causes. To gather the data, the researchers watched the series and highlighted some events that contained pragmatic failures. Then, the researchers used three steps of data analysis: gather and organize, categorize, and analyze the findings. The findings showed that there were 25 pragmatic failures that happened in the drama. They were caused by five reasons, namely failure in understanding others' intentions, failures in understanding others' state, denials to the reality, trauma, and failures in understanding a situation.
\end{abstract}

Keywords: pragmatic failures, 13 Reasons Why, analysis

\section{Introduction}

People nowadays can access everything with high technologies that they have. There is no place and time border. According to Schmitt (2015), "the music business was killed by Napster; movie theaters were derailed by digital streaming; traditional magazine are in crisis mode in this digital information era. Even people can download or watch movies and TV serial online.

One of the famous TV serials is Netflix drama series "13 Reasons Why". This drama is widely watched by youngsters all around the world, so it is labeled as the top trending TV show in 2017. The drama tells a story of a girl named Hannah Baker who commits suicide. During her high school, she undergoes some bullying in school. She tries to cope up with the bullying and tries to make up her relationships with her friends. However, her effort is in vain. The bullying still happens until she finally decides to commit suicide. But before she commits suicide, she makes a recording in tapes which tells who the ones who make her depressed are and what they do to her. Inside those tapes, Hannah only retells her story. Sometimes, what she says is true, but sometimes there are events who are 
misunderstood. Sometimes, the misunderstandings also reveal pragmatic failures between characters.

Due to the reason, the researchers of this study are interested in the pragmatic field related to the drama. According to Leech (1983), pragmatics is language study in use within a given context. In specific, "pragmatics includes the study of how the interpretation and use of utterances depends on knowledge of the real world; how speakers use and understand speech acts; how the structure of sentences is influenced by the relationship between the speaker and the hearer" (Lou \& Goa, 2011, p.183). In pragmatics, speakers' intention and listeners' interpretation of 'what is meant by what is said' are very important because there are variables in communication (Thomas, 1983; Shammas, 1995; Tang, 2013).

Some research reports have explored pragmatic failures as the theme. Most of them discovered pragmatic failures that happen between native speakers and nonnative speakers in the context of cross-cultural communication (Lihui\&Jianbin, 2010; Du, 2014). Then, there is a study of pragmatic failures within novels and the characters have autism syndrome (Semino, 2014). This study analyzes pragmatic failures in Netflix drama series "13 Reasons Why". Different with other studies, the pragmatic failures that happen in this drama occur within native speakers and without any autism syndrome. The knowledge in this study is expected to be helpful for educators and textbook writers to provide more detailed examples in linguistics. To guide this study, the researchers formulate one question: How many pragmatic failures occurred in TV drama series "13 Reasons Why" and what are their causes?

\section{Pragmatics}

Pragmatics is one branch of linguistics which studies meaning. Leech (1983) defines pragmatics as "the study of meaning in relation to speech situations" ( $p$. 6). Regarding pragmatics, Crystal (1992) says that it is "the study of language from the point of view of the users, especially of the choices they make, the constraints they encounter in using language in social interaction ..." (p. 57). From these points of view, it can be concluded that pragmatics studies the meaning of a language used by people in social communication.

Thomas (2013) explains that the meaning can be divided into two categories: speaker meaning and utterance meaning. Speaker meaning refers to the social view which "the focus of attention firmly on the producer of the message, but at the same time obscures the fact that the process of interpreting what we hear involves moving between several levels of meaning" (p. 2).Then, utterance meaning refers to cognitive view which "focusing too much on the receiver of the message, which in practice means largely ignoring the social constraints on utterance production" (p. 2). It means that people can identify the meaning behind sentences either within the speakers' point of view or the receivers' point of view.

\section{Pragmatic Failures}

Since pragmatics mainly focuses on meaning, people as speakers or receivers are required to understand what others intend to in their utterances. However, sometimes people fail to catch this meaning due to some reasons. This failure is what refers to pragmatic failure. Thomas (1983) defines pragmatic failure as the incompetence of people to understand what is said by others in terms of meaning. 
This failure is divided into two types: pragmalinguistic failure and sociopragmatic failure.

Pragmalinguistic failure generally "occurs when the pragmatic force mapped by $\mathrm{S}$ [speaker] onto a given utterance is systematically different from the force most frequently assigned to it by native speakers of the target language, or when speech act strategies are inappropriately transferred from L1 to L2" (Thomas, 1983, p. 99). Therefore, it means that the failure to catch meaning happens due to different systematical utterances between the speakers and receivers. Since there is a systematical difference in the utterances, pragmalinguistic failure is closely linked to linguistics. It is also related to the bias the hearers make during the conversations.

Different with pragmalinguistic failure, sociopragmatic failure is widely related to the social context. Thomas (1983) explains sociopragmatic failure as "a term I have appropriated from Leech (1983: 10-11), which I use to refer to the social conditions placed on language in use" (p. 99). It means that sociopragmatic failure is a pragmatic failure that happens due to social differences that take place in the occurrence. For example is a conversation between Western and Asian. In Western countries, when people visit someone's house and they are offered something to drink, they directly mentions a drink they want. Meanwhile, it does not happen for Asian. When Asian are offered something to drink, they tend to refuse it first for politeness purpose. From this illustration, it can be seen that there is a possibility for a pragmatic failure when the Asian and Western meet. Consequently, each party may find the others rude, whether for refusing the offer, or directly asking for a drink. Considering this matter, it becomes essential for people to understand the speakers and the receivers' social background in conversations. Also, regarding to this social and cultural context, sociopragmatic failure is also known as cross-cultural pragmatic failure.

Then, there are some reasons why sociopragmatic failure happens. Thomas (1983) mentions four causes of sociopragmatic failure. The first one is the size of imposition. This matter is related to a culture view of 'free goods' (Goffman, 1967). The second cause is tabus. Tabus is associated with some topics that are not common and not appropriate to be a topic in some countries. The third one is different assessment of relative power or social distance. Power and social distance in some countries may exist, but it may not exist in some others. The last reason is value judgments. When one of these causes appear in two persons' conversations, a pragmatic failure may happen. The easiest example can be taken from relative power and social distance matter. For instance, some foreigners who learn Indonesian may find it quite difficult to adjust the way Indonesian talk with elders or the ones with higher status. They might make mistakes in talking with elders and the ones with higher status by talking in informal language.

\section{Psychoanalysis}

Psychoanalysis was developed by Sigmund Freud in 1897. Rajeevan (2011) argues that psychoanalysis itself has three different meanings (as cited in Pangestu \& Sunardi, 2016). First, it is described as a school of psychology. It refers to the importance of childhood backgrounds in forming one's adult characteristics. Second, psychoanalysis is described as a specific method in investigating mental activities. And third, psychoanalysis is described as a therapeutic method for the investigation and treatment of mental disorders, especially the neurotic disorders. 
Pangestu and Sunardi (2016) argue that anxiety is related to psychoanalysis. Tyson (2006) states that anxiety causes nervousness, fear, and worrying. Anxiety happens when our defenses momentarily break down. It is an important moment because it can reveal our own core issues. According to Kathy (2015), core issues are issues which describe our behaviour that we carry through life. There are five common core issues:

a. Fear of intimacy: the chronic and overpowering feeling that emotional closeness will seriously hurt someone.

b. Fear of abandonment: the unshakable belief when friends or loved ones are going to leave.

c. Fear of betrayal: the feeling when friends or loved ones cannot be trusted anymore.

d. Low self-esteem: feel less worthy than other people.

e. Insecure or unstable sense of self: the inability to sustain a feeling of personal identity, a sense of knowing ourselves.

\section{Previous Studies}

Many studies have explored pragmatic failure as the main topic. As mentioned in the introduction part, many studies focus on the sociopragmatic failures which take place in cross-cultural communication. Luo (2016) explores pragmatic failures within cross-cultural communication between Chinese students or teachers and foreigners. The results showed that different cultures between Chinese and Western cause pragmatic failures in the communication. Then, a study by Economidou-Kogetsidis (2011) also discovers some pragmatic failures that are committed by Greek Cypriot university students, who are non-native speakers of English, in sending e-mail requests to their faculty. The analyzed emails are found to have some pragmatic failures which lead to rudeness and impoliteness. Last, a study by Semino (2014) research some pragmatic failures which happen between autism protagonists in three novels. The results of the study shows that there are three types of pragmatic failures that happen between the characters. They are "problems with informativeness and relevance in conversational contributions; problems with face management resulting in unintentional impolite behaviours; and problems with the interpretation of figurative language" (p. 141).

\section{Method}

This study aimed to identify and present pragmatic failures in Netflix TV Series "13 Reasons Why". Thus, a qualitative research design was used in this study. According to Patton and Cochran (2012), qualitative research is indicated by understanding social life aspects (p. 2). Since this study analyzed a TV series, the data in this study were gathered from the TV series scripts and the drama itself.

To gather the data, the researchers first watched the drama. The drama consisted of 13 episodes, and the researchers watched all of the episodes. By watching all of the episodes, the researchers were able to gain a big picture of the social life happens in the drama. After that, the researchers re-watched the series and highlighted some events that contained pragmatic failures. Last, the researchers found sentences that contained pragmatic failures in the script. The scripts were used as written documents to analyze the pragmatic failures. 
According to Ary, Jacobs, and Razavieh (2010), there are three stages in qualitative data analysis, namely organizing and familiarizing, coding and reducing, and interpreting and representing. In analyzing the data, the researchers used three steps of data analysis. First, the researchers gathered and organized the TV series' scripts from the English subtitles as a part of the instruments. They were used also as the written documents to identify the pragmatic failures. Second, the researchers coded the transcripts and categorize the sentences. The researchers also reduced the unneeded data in order to focus on the problem of study. After that, the researchers analyzed the pragmatic failures that happen in the series based on the scripts and also the videos. The researchers represented the data by generating words instead of numbers.

\section{Findings and Discussion}

Based on the data analysis, the researchers found 25 pragmatic failures that happened in the drama series. These pragmatic failures happened because of at least 5 reasons namely failure in understanding others' intentions, failures in understanding others' state, denials to the reality, trauma, and failures in understanding a situation. Thus, the types of pragmatic failures that occurred in this drama were considered as sociopragmatic failures (Thomas, 1983) since there were no pragmatic failures that occurred because of different pragmatic systems.

\section{Failures in Understanding Others' Intention}

In the drama series, the researchers found at least six pragmatic failures that occurred because of the inability to understand others' intentions. In this case, the speakers tried to convey an intention within their language. However, the receivers failed to catch the intention. This failure led to an inappropriate reply of the receivers, and it often caused misunderstandings between the speakers and the receivers. Low self-esteem is feeling less worthy than other people (Kathy, 2015). Low self-esteem feelings are based on the backgrounds and experiences which happened in life. If the experiences have been negative for someone, the beliefs about her/himself are likely to be negative too. One of the example can be seen from the conversation between Hannah's mom and dad.

\footnotetext{
Hannah's dad : Honey? You okay?

Hannah's mom : I was just thinking it's a bad sign that we're... running out of "Buy One, Get One Free" stickers.

Hannah's dad : We can look at it as a bad sign or we can consider it the world telling us we can never discount our way to Walplex prices.

(silent moment)

Hannah's dad : I've got more stickers back here somewhere.
}

From the conversation above, it can be seen that Hannah's mom tried to ask for more "Buy One Get One Free" stickers from Hannah's dad. However, Hannah's dad only took it as a joke. This misunderstanding made Hannah's mom a little bit upset, marked by a silent moment which Hannah's mom made.

\section{Failures in Understanding Others' State}

The misunderstandings that occur in the drama also occurred due to failures in understanding others' state. It means that the speakers failed to understand the receivers' state in uttering sentences. This cause was the biggest cause of 
pragmatic failures in this drama with seven pragmatic failures identified. The example of this case can be seen below in the conversation between Clay and Hannah. The conversation takes place when the students in the high school made a hot list. Then, Hannah got one of the awards which were the hottest butt. Hannah was hurt by the list, but Clay did not understand that.

Hannah: High school is bullshit.

Clay : Yeah. Don't disagree. But... any specifics?

Hannah: I wish there was a button to fast-forward you through all the shitty parts in life straight to the good parts.

Clay : And where are the good parts?

Hannah: College. In New York City.

Clay : Why New York?

Hannah: The minute I get there, I can be someone else. Whoever I want to be.

Clay : But who you are now is okay.

Hannah: Okay? High praise. Thank you.

Clay : I mean, is awesome. You're... I mean, you made the hot list.

Hannah: Seriously, Clay?

Clay : What? They said you had the best... That's out of a lot of good candidates. Not that I've surveyed, I'm just saying.

Hannah: What if girls made a list and you got... worst biceps.

Clay : Girls would probably never do that list.

Hannah: Precisely.

Clay : And my biceps are at least better than Alex's.

Hannah: That kid hasn't lifted so much as a carton of milk in years, I think. Once again, you and the point are complete strangers.

In the conversation above, it can be seen that Clay did not understand that actually Hannah was hurt by the hot list. Hence, he said that it was awesome for Hannah to be one of those lists. However, Hannah also did not understand that Clay did not care about the list. Hannah had tried to make Clay understand how she felt by asking him how it was if the girls voted him to be the worst biceps. However, Clay did not catch that meaning and made Hannah upset. Hannah's upset can be seen from her last sentence which stated that Clay did not understand Hannah.

Because of the hotlist, Hannah was feeling insecure. Insecure or unstable sense of self is the inability to sustain a feeling of personal identity, a sense of knowing ourselves (Kathy, 2015). In other words, Hannah was being insecure because she did not have confidence in herself and a situation she was in. She did not have any confidence to face her friends because of the hotlist. Hannah put herself down around other students in a way, and her behaviour actually highlighted her insecurities. Even she refused to take responses from Clay who did not care to the hotlist. She pointed out that all the things happened were actually not fine for her.

\section{Denials to the Reality}

When the two cases above focused on the speakers' failures in understanding others, this case paid more attention to the receivers' view. One of the causes of pragmatic failures in this drama is denials to the reality. For instance of this case is the conversation between Skye and Courtney in communication class. The 
communication class asked every student to have a bag of compliment for each student. However, instead of getting anonymous compliments, the students' bag was filled by Courtney's leaflets for students' president selection. Once, Skye was upset by that and confessed to the Courtney her disappointment.

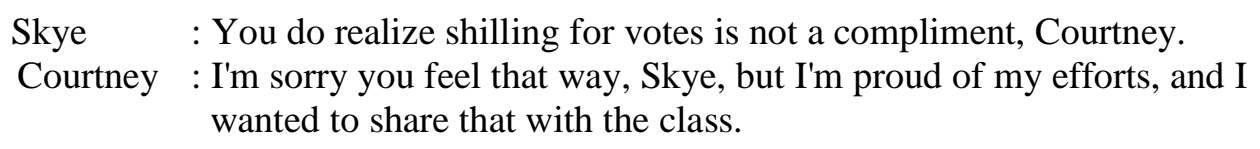

From the conversation between Skye and Courtney above, Courtney did not want to accept the reality that Skye was bothered by her leaflet. Thus, she decided to deny the meaning that was conveyed by Skye by denying the reality.

Courtney chose to deny the reality because she had fear of abandonment. Fear of abandonment is the unshakable belief when others are going to leave (Kathy, 2015). Mostly, people grow up with fears of abandonment in themselves. Everyone has this kind of fear at various levels. Most of people have anxiety over thoughts of rejection. Courtney did not want to be rejected by her friends in students' president selection. As the result, she filled others' compliment bags with her leaflets. Moreover, when Skye told Courtney that what Courtney did was annoying, Courtney did not want to accept that because she did not want to be rejected. This fear of being rejected is what causes pragmatic failures occur.

\section{Trauma}

Trauma is also one of the causes of misunderstandings that occur between characters in the drama. The trauma may happen to one of the characters. Meanwhile, either the speakers or the receivers sometimes do not consider others' trauma in the conversation. This cause was the most minor cause to the pragmatic failures that occurred in this drama. There were only three pragmatic failures that were identified caused by trauma. The example can be seen in the conversation between Tyler and Hannah. Hannah got a trauma for being captured in photos by Tyler because the last time Tyler captured Hannah and Courtney's photo, Hannah was accused for being a lesbian.

Hannah: Seriously, Tyler?

Tyler : It's for the yearbook.

Hannah: I don't care. Don't put it in my face.

The conversation above takes place when Tyler was trying to take Hannah's photo in a prom night. When Tyler tried to convince Hannah that the photos he took were for yearbook, Hannah did not want to understand Tyler because of the trauma she got from Tyler.

In this case, the pragmatic failure that happened between Tyler and Hannah was case by Hannah's fear of betrayal (Kathy, 2015). The last time Tyler took a photo of Hannah, Hannah was accused of being a lesbian. It made her scared of being taken in a photo. So, when Tyler took a picture of Hannah, even though it was for yearbook, Hannah did not want to understand that, in case that the photo would be used for something else. 


\section{Failures in Understanding a Situation}

One source of pragmatic failures in this drama is failures in understanding a situation. When speakers and receivers talk to each other, situation plays an important role in understanding one's meaning. If the situation is understood properly, it may lead to misunderstandings between speakers and receivers. For instance is the conversation between Hannah and a shopkeeper. When Hannah was involved in an accident, Hannah was trying to get a help from a shopkeeper to call 911. However, the shopkeeper did not respond to Hannah's request because the shopkeeper did not understand the situation.

Hannah : I need help. My phone's dead.

Shopkeeper: Chargers are right over there by the beef jerky.

Hannah : No listen. There's been an accident. I need to make a call.

Shopkeeper: Sorry, we don't have a pay phone.

Hannah : Give me your phone. Give me your phone!

As can be seen from the conversation, because the shopkeeper did not understand the situation, the shopkeeper guided Hannah to the phone charging place. Meanwhile, Hannah's meaning is asking the shopkeeper to lend her his phone. However, even though Hannah had stated her intention, the shopkeeper still did not understand Hannah's meaning. Until Hannah explicitly mentioned that she wanted to borrow the shopkeeper's phone, the shopkeeper just lent her the phone. The failures in understanding the situation that happens during the conversation makes either the speakers or the receivers angry. Thus, it is important to understand situations between speakers and receivers in a conversation.

\section{Conclusion}

This study aimed to find out pragmatic failures that occurred in TV drama series "13 Reasons Why" and their causes. In conclusion, the researchers found that there were 25 pragmatic failures that occurred in this drama and they were caused by 5 reasons, namely failure in understanding others' intentions, failures in understanding others' state, denials to the reality, trauma, and failures in understanding a situation. From the findings, the researchers found that the major cause of pragmatic failures in the TV drama series was failures in understanding others' state. There were seven failures in understanding others' state there. From the TV drama script, the researcher found that the characters failed to understand the others' state in uttering sentences. Then, the smallest cause of pragmatic failures was trauma. In the TV drama series, there were only three examples of pragmatic failures because of trauma. The characters in the drama series, either the speakers or the receivers sometimes did not consider others' trauma in the conversation. In general, the findings show that pragmatic failures happened in "13 Reasons Why" and there were 5 causes of them. By analyzing pragmatic failures, this study showed that speakers' speaking style can cause misunderstanding to the listeners. The findings also signal that this drama can be a source for educators to provide more detailed examples in pragmatic failures. 


\section{References}

Ary, D., Jacobs, L. C., \& Sorensen, C. (2010). Introduction to research in education ( $8^{\text {th }}$ ed.). Belmont: Wadsworth Cengage Learning.

Crystal, D. (1992). Introducing linguistics. London: Penguin.

Economidou-Kogetsidis, M. (2011). "Please answer me as soon as possible": Pragmatic failure in non-native speakers' e-mail requests to faculty. Journal of Pragmatic, doi:10.1016/j.pragma.2011.06.006

Kathy, P. (2015). Psychoanalysis: The defenses, anxiety and core issues. Educational Website Content Management.

Leech, G. (1983). Principles of Pragmatics. New York: Longman.

Luo, R. (2016). Analysis of pragmatic failure and pragmatic ability formation in English teaching. $2^{\text {nd }}$ International Conference on Humanities and Social Science Research.

Luo, X. \& Goa, J. (2011). On pragmatic failures in second language learning. Theory and Practice in Language Studies, 1(3), 283-286.

Pangestu, N. A. \& Sunardi, F.X. D. (2016). An incomplete psychological novel: A psychoanalytical analysis of hazel Lancaster in John Green's The Fault in Our Stars. Journal of Language and Literature, 16(1), 20-28.

Semino, E. (2014). Pragmatic failure, mind style and characterisation in fiction about autism. Language and Literature, 23(2), 141-158.

Shammas, N. A. (2005). Lingua-pragmatic politeness and translatability. Damascus University Journal, 21(3\&4), 23-56.

Tang, J. (2013). Analysis of pragmatic failure from the perspective of adaptation. Cross-Cultural Communication, 9(3), 75-79.

Thomas, J. (1983). Cross-cultural pragmatic failure. Applied Linguistics, 4(2), 91112.

Thomas, J. (2013). An introduction to pragmatics. New York: Routledge.

Tyson, L. (2006). Critical theory today. New York: Routledge. 